\title{
Visit-to-visit HbA1c variability is inversely related to baroreflex sensitivity independently of HbA1c value in type 2 diabetes
}

\author{
Daisuke Matsutani ${ }^{1 \dagger}$, Masaya Sakamoto $^{1 *+}$ (D) Soichiro Minato ${ }^{1}, Y$ Yosuke Kayama ${ }^{2}$, Norihiko Takeda ${ }^{3}$, \\ Ryuzo Horiuchi ${ }^{4}$ and Kazunori Utsunomiya ${ }^{1}$
}

\begin{abstract}
Background: The relationship between long-term glycemic variability (GV) represented by visit-to-visit HbA1c variability and baroreflex sensitivity (BRS) in type 2 diabetes mellitus (T2DM) has not been clarified by previous literature. The present study is the first to examine the relationships between visit-to-visit HbA1c variability and BRS.

Methods: This retrospective study initially analyzed data on 94 patients with T2DM. Visit-to-visit HbA1c variability was evaluated using the intrapersonal coefficient of variation (CV), standard deviation (SD), and adjusted SD of 8 or more serial measurements of $\mathrm{HbA} 1 \mathrm{c}$ during a 2-year period. The BRS was analyzed using the sequence method. Short-term GV was assessed by measuring the glucose CV during 24-h continuous glucose monitoring (CGM). The primary objective was to determine if there was a relationship between visit-to-visit $\mathrm{HbA1c}$ variability ( $\mathrm{HbA} 1 \mathrm{c} C \mathrm{CV}$ ) and BRS. Secondary objectives were to examine the relationship between other variables and BRS and the respective and combined effects of long-term GV (HbA1c CV) and short-term GV (CGM CV) on BRS.

Results: A total of 57 patients (mean age 67.2 \pm 7.7 years, mean HbA1c $7.3 \pm 1.0 \%$ ) who met this study's inclusion criteria were finally analyzed. In the univariate analysis, HbA1c CV $(r=-0.354, p=0.007)$, HbA1c SD $(r=-0.384$, $p=0.003)$, and adjusted HbA1c SD $(r=-0.391, p=0.003)$ were significantly related to low levels of BRS. Multiple regression analysis showed that $\mathrm{HbA} 1 \mathrm{C} C V, \mathrm{HbA1} C \mathrm{SD}$, and adjusted $\mathrm{HbA1} \mathrm{C}$ SD were inversely related to BRS. Furthermore, although the increase in either long-term GV (HbA1c CV) or short-term GV (CGM CV) as determined by 24-h CGM was inversely correlated with BRS, additional reductions in BRS were not shown in participants with both HbA1C CV and CGM CV values above the median.
\end{abstract}

Conclusions: Visit-to-visit HbA1c variability was inversely related to BRS independently of the mean HbA1c in patients with T2DM. Therefore, visit-to-visit HbA1c variability might be a marker of reduced BRS in T2DM.

Keywords: Visit-to-visit glycemic variability, Long-term glycemic variability, Short-term glycemic variability, Baroreflex sensitivity, Cardiovascular autonomic neuropathy, Continuous glucose monitoring, Type 2 diabetes mellitus

*Correspondence: m-sakamoto@umin.ac.jp

${ }^{\dagger}$ Daisuke Matsutani and Masaya Sakamoto contributed equally to this

study

${ }^{1}$ Division of Diabetes, Metabolism and Endocrinology, Department

of Internal Medicine, Jikei University School of Medicine, 3-25-8,

Nishi-Shinbashi, Minato-ku, Tokyo 105-8461, Japan

Full list of author information is available at the end of the article

(c) The Author(s) 2018. This article is distributed under the terms of the Creative Commons Attribution 4.0 International License (http://creativecommons.org/licenses/by/4.0/), which permits unrestricted use, distribution, and reproduction in any medium, provided you give appropriate credit to the original author(s) and the source, provide a link to the Creative Commons license, and indicate if changes were made. The Creative Commons Public Domain Dedication waiver (http://creativecommons.org/ publicdomain/zero/1.0/) applies to the data made available in this article, unless otherwise stated. 


\section{Background}

Baroreflex sensitivity (BRS), which is a sensitive indicator of cardiovascular autonomic neuropathy (CAN) in type 2 diabetes mellitus (T2DM) [1, 2], has been found to be associated with cardiovascular events [3-5]. In T2DM, the cause of reduced BRS has not been fully elucidated. Reductions in BRS have been reported to be associated with hyperglycemia [6-8], older age [9, 10], obesity [9, $11]$, hypertension $[9,10,12]$, dyslipidemia [10, 13, 14], and increased heart rate $[9,10]$. Chronic hyperglycemia is known to be an important cause of reduced BRS in T2DM, and recently we reported that short-term glycemic variability (GV) determined by continuous glucose monitoring (CGM) was inversely related to BRS independently of blood glucose levels [15]. Short-term GV also was reported to be associated with CAN as measured by means other than BRS, such as heart rate variability (HRV) [16] in T2DM; moreover, in type 1 diabetes this relationship was similar to that in T2DM $[17,18]$. Recently, not only short-term GV but also long-term GV represented by visit-to-visit HbA1c variability, which is an independent risk factor for cardiovascular events [19-22], were reported as risk factors for CAN [16]. Furthermore, it was reported that visit-to-visit HbA1c variability was a predictor of new-incident peripheral neuropathy [19], and that visit-to-visit glycated albumin variability was significantly associated with the risk of developing CAN in T2DM [23]. Long-term GV refers to glycemic fluctuations over months to years and is generally described as visit-to-visit variability in either HbA1c or fasting blood glucose in T2DM. However, the relationship between such long-term GV represented by visit-tovisit HbA1c variability and BRS has not been clarified.

The present study is the first to examine the relationships between visit-to-visit HbA1c variability and BRS.

\section{Methods}

\section{Study participants}

This study retrospectively analyzed data from a previous study on patients whose HbA1c was measured 8 or more times during a 2-year period, including HbA1c values obtained on the first day of BRS measurements [15]. All of the time intervals between HbA1c measurements were within 3 months. The primary objective was to determine if there was a relationship between visit-to-visit HbA1c variability [HbA1c coefficient of variation $(\mathrm{CV})]$ and BRS. Secondary objectives were to examine if there were relationships between BRS and (1) other measurements for evaluating visit-tovisit $\mathrm{HbA} 1 \mathrm{c}$ variability [HbA1c standard deviation (SD) and adjusted HbA1c SD]; short-term GV (CGM CV and CGM SD) as determined by CGM; other glycemic control variables such as 2-year mean HbA1c, baseline fasting plasma glucose, and baseline HbA1c level; heart rate; systolic blood pressure (SBP) and diastolic blood pressure (DBP); age; body mass index (BMI); lipid metabolism variables such as triglycerides, low-density lipoprotein (LDL) cholesterol, and high-density lipoprotein (HDL) cholesterol; (2) respective and combined effects of long-term GV (HbA1c CV) and short-term GV (CGM CV) on BRS; and (3) comparison of BRS and visit-to-visit HbA1c variability according to subgroups. The baseline examination was conducted at Jikei University School of Medicine Hospital, Tokyo, Japan and Tsuruoka kyoritsu Hospital, Yamagata, in 2017. Details of inclusion and exclusion criteria were described previously [15]. Briefly, inclusion criteria for that study were age $\geq 40$ years and the presence of T2DM diagnosed according to 2017 American Diabetes Association guidelines. Exclusion criteria included arrhythmia, malignancy, and insulin-dependent diabetes mellitus, but did not exclude those with hypertension and dyslipidemia. An additional inclusion criterion in the present study was measurement of HbA1c 8 or more times during a 2-year period. Additionally excluded from the analysis in the current study were patients who had not made an outpatient visit for 2 years or more, had an insufficient number of $\mathrm{HbA} 1 \mathrm{c}$ readings during 2 years, and who had been hospitalized due to any disease in the past 2 years (Fig. 1).

Of the 94 people who were finally analyzed for our previous study [15], 57 patients who met this study's inclusion criteria were finally analyzed after excluding 32 patients who had not made an outpatient visit for 2 years or more, 4 patients with an insufficient number of $\mathrm{HbA} 1 \mathrm{c}$ readings during 2 years, and 1 patient who had been hospitalized in the past 2 years (Fig. 1).

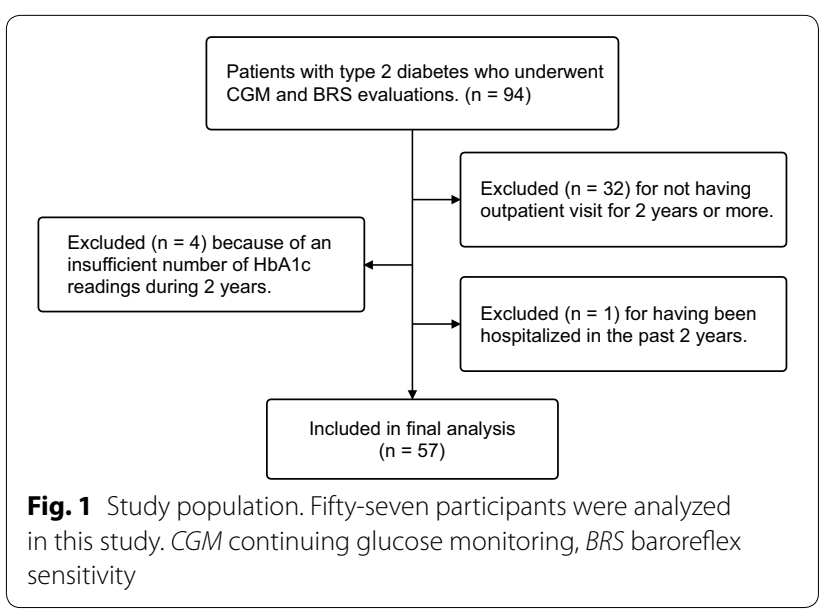




\section{Assessment of visit-to-visit glycemic variability}

Visit-to-visit HbA1c variability was evaluated using the intrapersonal CV, SD, and adjusted SD of 8 or more serial measurements of HbA1c during a 2-year period, including that obtained on the first day of measuring BRS (Fig. 2). HbA1c was measured 14.8 \pm 4.7 times (mean $\pm S D$ ) during the 2-year period. To adjust for the effect of varying numbers of HbA1c measurements among study patients, the adjusted SD of HbA1c was given as the SD of HbA1c divided by $[n /(n-1)]^{0.5}$, where $\mathrm{n}$ is the number of HbA1c measurements [24].

\section{Assessment of baroreflex sensitivity}

Baroreflex sensitivity was evaluated on the first day of hospitalization in the previous study (Fig. 2) [15]. Using the spontaneous sequence method the beat-to-beat blood pressure (BP) was measured for $15 \mathrm{~min}$ after $15 \mathrm{~min}$ of supine rest as the slope of the relationship between spontaneous changes in SBP and the pulse interval. Beat-tobeat BP was measured using the second and third fingers of the right hand by the vascular unloading technique. A standard 3-lead electrocardiogram was used to record the heart rate. In calculating BRS, the relative changes in BP ( $\mathrm{mmHg}$ ) and the $\mathrm{R}-\mathrm{R}$ interval (msec), which is expressed as the distance between corresponding QRS complexes, were determined by the sequence method using cut-off points of $1 \mathrm{mmHg}$ and $3 \mathrm{~ms}$, respectively (Task Force Monitor, CNSystems, Graz, Austria) [25, 26].

\section{Statistical analyses}

Patients' characteristics and results are presented as mean $\pm S D$ or median with interquartile range (IQR) as appropriate according to the data distribution. Pearson's correlation analysis or Spearman's rank correlation coefficient test were used for single correlations (Table 2). Multiple-linear regression was used to assess individual and cumulative effects of visit-to-visit HbA1c variability (CV, SD, and adjusted SD), 2-year mean HbA1c, CGM $\mathrm{CV}$, age, sex, BMI, SBP, LDL-cholesterol, and heart rate on BRS. Independent variables were selected based on previous studies of factors associated with low levels of BRS [6-15] (Table 3). As shown in Table 4, individuals were grouped according to CGM CV and $\mathrm{HbA1c} C \mathrm{CV}$. Group 1 was the reference group and included participants with both CGM CV and HbA1c CV values below the respective median values. Participants in Group 2 had CGM CV values above the median and those in Group 3 had HbA1c CV values above the median. In Group 4 participants had both CGM CV and HbA1c $\mathrm{CV}$ values above the median. The analysis of variance (ANOVA) or the Kruskal-Wallis test was used to compare BRS and other variables among the four groups and the Jonckheere trend test was used to test for linear trends in BRS for the four groups. In ANOVA, the Tukey post hoc test or the Games-Howell post hoc test compared results of the BRS and other variables among the four groups. In the Kruskal-Wallis test, the Bonferroni post hoc test compared results of the HbA1c CV among the four groups. As shown in Table 5, HbA1c CV, HbA1c $\mathrm{SD}$, adjusted HbA1c SD, and BRS were divided into the following subgroups: sex, hypertension, dyslipidemia, insulin use, sulfonylurea use, statin use, renin-angiotensin-aldosterone system (RAAS) inhibitor use, calciumchannel blocker use, and beta-blocker use. In subgroup analysis, each parameter was compared using the Student's $t$ test or nonparametric Mann-Whitney $U$ test. For data analyses the Statistical Package for the Social Sciences 22.0 software was used (IBM, Armonk, NY, USA). A $p$ value $<0.05$ was considered significant.

\section{Results}

\section{Baseline characteristics of study participants}

A total of 57 patients were finally analyzed. Baseline clinical and anthropometric characteristics of the study participants are shown in Table 1 . The prevalence of study participants ever diagnosed with hypertension or dyslipidemia was 74 or $89 \%$, respectively. The mean age of participants was $67.2 \pm 7.7$ years, mean duration of diabetes was $11.5 \pm 9.6$ years, mean number of HbA1c measurements was $14.8 \pm 4.7$ times, and average of the 2 -year

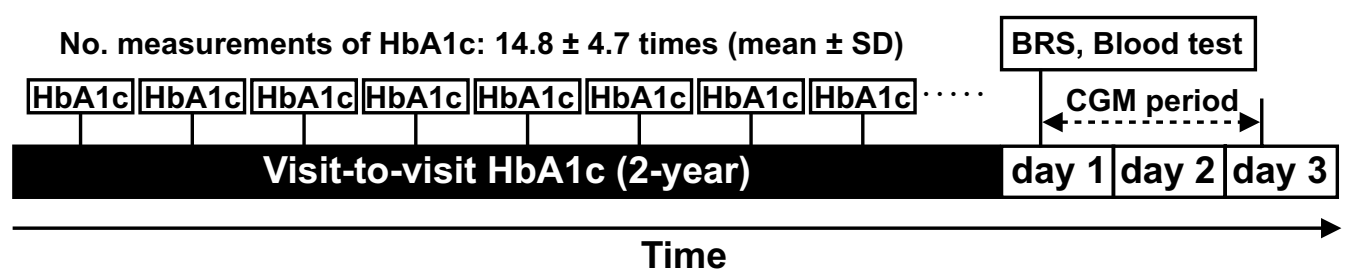

Fig. 2 Study protocol. Visit-to-visit HbA1c variability was evaluated using HbA1c values obtained 8 or more times during a 2-year period, including $\mathrm{HbA} 1 \mathrm{c}$ values obtained on the first day of measurement of BRS. All of the time intervals between $\mathrm{HbA} 1 \mathrm{c}$ measurements were within 3 months. BRS baroreflex sensitivity, CGM continuous glucose monitoring, SD standard deviation 
Table 1 Baseline clinical characteristics of the participants or patients study participants

\begin{tabular}{|c|c|}
\hline Variables & \\
\hline No. patients & 57 \\
\hline Sex, male/female & $39 / 18$ \\
\hline Age (years) & $67.2 \pm 7.7$ \\
\hline BMI $\left(\mathrm{kg} / \mathrm{m}^{2}\right)$ & $25.4 \pm 4.2$ \\
\hline Duration of diabetes (years) & $11.5 \pm 9.6$ \\
\hline Fasting plasma glucose (mg/dL) & $134.7 \pm 30.7$ \\
\hline $\mathrm{HbA1c}(\%)$ & $7.3 \pm 1.0$ \\
\hline \multicolumn{2}{|l|}{ Long-term data } \\
\hline $\begin{array}{l}\text { No. HbA1c measurements in } 2 \text { years } \\
\text { (times/2 years) }\end{array}$ & $14.8 \pm 4.7$ \\
\hline Two-year mean HbA1c (\%) & $7.2 \pm 1.0$ \\
\hline $\mathrm{HbA1c} C V(\%)$ & $0.049(0.029-0.080)$ \\
\hline $\mathrm{HbA} 1 \mathrm{c} \mathrm{SD}(\%)$ & $0.33(0.18-0.62)$ \\
\hline Adjusted HbA1c SD (\%) & $0.32(0.18-0.59)$ \\
\hline \multicolumn{2}{|l|}{ Short-term data } \\
\hline CGM mean glucose (mg/dL) & $154.5 \pm 28.8$ \\
\hline CGM CV (mg/dL) & $23.6 \pm 7.1$ \\
\hline CGM SD (mg/dL) & $36.7 \pm 13.2$ \\
\hline Hypertension, n (\%) & $42(74)$ \\
\hline \multicolumn{2}{|l|}{ Blood pressure $(\mathrm{mmHg})$} \\
\hline Systolic & $124.6 \pm 17.0$ \\
\hline Diastolic & $77.1 \pm 9.4$ \\
\hline Heart rate (beats/min) & $69.3 \pm 11.8$ \\
\hline Dyslipidemia, n (\%) & $51(89)$ \\
\hline \multicolumn{2}{|l|}{ Lipid profile (mg/dL) } \\
\hline Triglycerides & $115(100-175)$ \\
\hline LDL-cholesterol & $111.0 \pm 30.2$ \\
\hline HDL-cholesterol & $52.8 \pm 15.5$ \\
\hline BRS (msec/mmHg) & $7.6 \pm 2.7$ \\
\hline
\end{tabular}

Values are mean $\pm S D$, or median (25th-75th percentiles) or no. (\%)

$B M I$ body mass index, $S D$ standard deviation, $C V$ coefficient of variation, $C G M$ continuous glucose monitoring, $L D L$ low-density lipoprotein, $H D L$ high-density lipoprotein, $B R S$ baroreflex sensitivity

mean HbA1c was $7.2 \pm 1.0 \%$. Median HbA1c CV was 0.049\% (IQR 0.029-0.080\%), median HbA1c SD 0.33\% (IQR 0.18-0.62\%), and median adjusted HbA1c SD was $0.32 \%$ (IQR 0.18-0.59\%).

\section{Univariate correlates of baroreflex sensitivity}

Correlation analysis showed that parameters of visit-tovisit $\mathrm{HbA1c}$ variability, such as $\mathrm{HbA1c} \mathrm{CV}(r=-0.354$, $p=0.007)$, HbA1c SD $(r=-0.384, \quad p=0.003)$, and adjusted HbA1c SD ( $r=-0.391, p=0.003)$, were significantly related to low levels of BRS. In addition to visitto-visit HbA1c variability, the level of BRS correlated with the 2-year mean HbA1c $(r=-0.384, p=0.003)$, CGM CV $(r=-0.325, p=0.014)$, CGM SD $(r=-0.366$, $p=0.005)$, heart rate $(r=-0.446, p=0.001)$, and age $(r=-0.358, p=0.006)$ (Table 2, Fig. 3).

\section{Multiple regression analysis of baroreflex sensitivity}

Multiple regression analysis showed that HbA1c CV, HbA1c SD, and adjusted HbA1c SD were inversely related to BRS. These findings remained after adjusting BRS for the 2-year mean HbA1c, CGM CV, age, sex, BMI, SBP, LDL-cholesterol, and heart rate. In addition to parameters of visit-to-visit HbA1c variability, age, CGM $\mathrm{CV}$, and heart rate were found to be predictive factors for BRS (Table 3).

\section{Respective and combined effects of short-term and long-term glycemic variability on baroreflex sensitivity} Table 4 shows comparisons of BRS among the four groups based on ANOVA. Group 1 included participants with both CGM CV and HbA1c CV values below the respective median values while Group 2 included only participants with CGM CV values above the median and Group 3 included only participants with $\mathrm{HbA1c} \mathrm{CV}$ values above the median. In Group 4 participants had both CGM CV and HbA1c CV values above the median. There was a significant difference in BRS among these four groups $(p=0.004)$. The results were then analyzed by the Tukey post hoc test. Group $2(p=0.045)$, Group $3(p=0.012)$, and Group $4(p=0.009)$ had reduced BRS in comparison with Group 1 (Table 4, Fig. 4). However, Group 4 did not have reduced BRS in comparison with Group $2(p=0.963)$ and Group $3(p=1.000)$. This observation was confirmed by the Jonckheere trend test: BRS $(p=0.002)$ showed a significant decreasing trend from Group 1 to Group 4.

\section{Comparison of baroreflex sensitivity in subgroups}

Use of sulfonylurea was associated with low levels of BRS compared with its non-use (sulfonylurea use vs. non-use: $6.4 \pm 2.1$ vs. $8.1 \pm 2.8 \mathrm{~ms} / \mathrm{mmHg}, p=0.028)$. The HbA1c $\mathrm{CV}, \mathrm{HbA1c} \mathrm{SD}$, and adjusted HbA1c SD in patients taking sulfonylurea were larger than in those who did not (sulfonylurea use vs. non-use: median HbA1c CV 0.065\% [IQR $0.035-0.103 \%$ ] vs. $0.047 \%$ [IQR $0.025-0.065 \%$ ], $p=0.043$; median HbA1c SD $0.60 \%$ [IQR $0.26-0.88 \%$ ] vs. $0.32 \%$ [IQR $0.16-0.47 \%$ ], $p=0.018$; median adjusted HbA1c SD 0.59\% [IQR 0.25-0.85\%] vs. 0.30\% [IQR 0.16$0.46 \%], p=0.015$ ). Hypertension and statin use were associated with low levels of BRS (hypertensive vs. normotensive: $7.0 \pm 2.5$ vs. $9.1 \pm 2.9 \mathrm{~ms} / \mathrm{mmHg}, p=0.011$; statin use vs. non-use: $6.6 \pm 2.6$ vs. $8.1 \pm 2.6 \mathrm{~ms} / \mathrm{mmHg}$, $p=0.035)$. However, there was no significant relationship between the mean BRS and sex, dyslipidemia, and the use of insulin, RAAS inhibitors, calcium-channel blockers, and beta-blockers (Table 5). 
Table 2 Univariate correlates of baroreflex sensitivity

\begin{tabular}{|c|c|c|}
\hline Variables & $r$ & $p$ \\
\hline Fasting plasma glucose (mg/dL) & -0.173 & 0.199 \\
\hline $\mathrm{HbA1c}(\%)$ & -0.337 & 0.010 \\
\hline \multicolumn{3}{|l|}{ Long-term data } \\
\hline Two-year mean HbA1c (\%) & -0.384 & 0.003 \\
\hline $\mathrm{HbA1c} C V(\%)$ & -0.354 & 0.007 \\
\hline HbA1c SD (\%) & -0.384 & 0.003 \\
\hline Adjusted HbA1c SD (\%) & -0.391 & 0.003 \\
\hline \multicolumn{3}{|l|}{ Short-term data } \\
\hline CGM mean glucose (mg/dL) & -0.238 & 0.074 \\
\hline CGM CV (mg/dL) & -0.325 & 0.014 \\
\hline CGM SD (mg/dL) & -0.366 & 0.005 \\
\hline Heart rate (beats/min) & -0.446 & 0.001 \\
\hline $\mathrm{SBP}(\mathrm{mmHg})$ & 0.154 & 0.252 \\
\hline $\mathrm{DBP}(\mathrm{mmHg})$ & 0.092 & 0.498 \\
\hline Age (years) & -0.358 & 0.006 \\
\hline $\mathrm{BMI}\left(\mathrm{kg} / \mathrm{m}^{2}\right)$ & 0.006 & 0.965 \\
\hline Triglycerides (mg/dL) & 0.085 & 0.527 \\
\hline LDL-cholesterol (mg/dL) & 0.074 & 0.586 \\
\hline HDL-cholesterol (mg/dL) & -0.088 & 0.514 \\
\hline
\end{tabular}

$C V$ coefficient of variation, $S D$ standard deviation, $C G M$ continuous glucose monitoring, SBP systolic blood pressure, $D B P$ diastolic blood pressure, $B M I$ body mass index, $L D L$ low-density lipoprotein, $H D L$ high-density lipoprotein

\section{Discussion}

This is the first clinical study to assess the relationship between BRS and long-term GV as represented by visitto-visit HbA1c variability. We retrospectively assessed data on patients with T2DM whose HbA1c was examined 8 or more times during the 2 years beginning from the time of recruitment for participation in our previous prospective study [15].

The results showed that visit-to-visit HbA1c variability was inversely correlated with BRS (Table 2, Fig. 3). In the multiple regression analysis, visit-to-visit HbA1c variability was independently associated with a decrease in BRS (Table 3). Furthermore, although the increase in either long-term GV or short-term GV was inversely correlated with BRS, an additional reduction in BRS was not shown in participants with both long-term GV and short-term GV values above the median (Table 4, Fig. 4). As in previous reports, our analysis showed that age and heart rate were also independent predictors of BRS [9, 10] (Tables 2, 3).

Long-term GV emerged as another measure of glycemic control that better predicted cardiovascular events [19-22] and microvascular complications [19, 21, 27, 28 ] than the average HbA1c level. Since there has been more evidence that long-term GV was related to prognosis and microvascular complications than short-term GV [29-34], long-term GV may confirm the prognosis to a greater extent. This is the first clinical study to investigate the association between long-term GV and BRS that can quantitatively and sensitively evaluate CAN [1]. Our results further support existing data showing that there was an independent association of visit-to-visit HbA1c variability with the presence of CAN [16] and that visitto-visit HbA1c variability was a predictor of new-incident peripheral neuropathy [19]. Also we noted that visit-to-visit glycated albumin variability was significantly associated with the risk of developing CAN in T2DM as previously reported [23].

Several potential mechanisms may link increased GV to the reduced BRS from a pathophysiological point of view. Previous studies suggested that increased GV causes the reduced BRS by inducing endothelial dysfunction and increasing oxidative stress independently of chronic hyperglycemia. For example, GV was shown to induce endothelial dysfunction [35-38], which subsequently causes neuropathy [39-42]. GV increased oxidative stress [36-38, 43] causing neuropathy $[44,45]$. In particular, vascular endothelial dysfunction leads to hypoxia and blood flow disorders in neuronal cells [39, 40], which might result in autonomic dysfunction. However, since
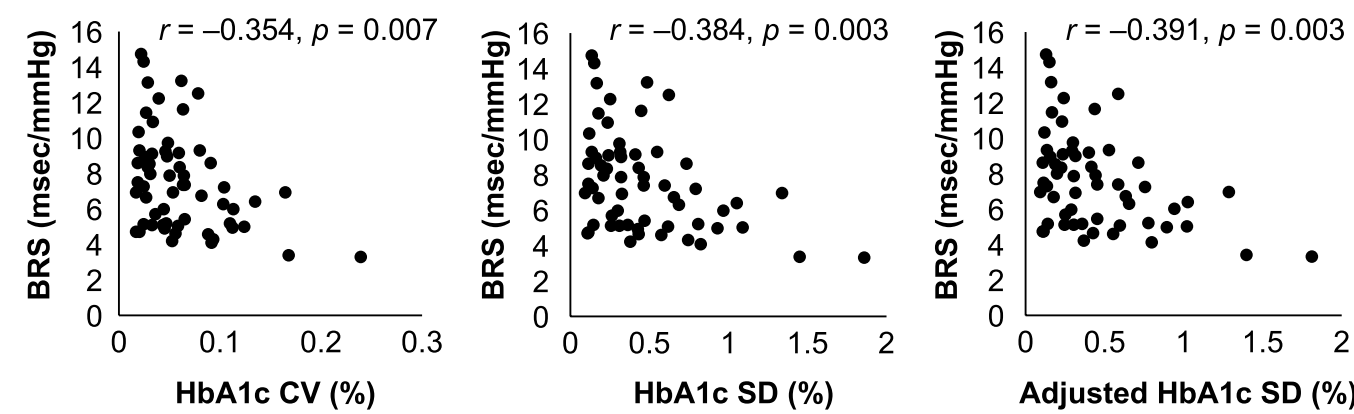

Fig. 3 Relationship between visit-to-visit $\mathrm{HbA1}$ c variability and baroreflex sensitivity. BRS baroreflex sensitivity, CV coefficient of variation, SD standard deviation 
Table 3 Multiple regression analysis of baroreflex sensitivity

\begin{tabular}{|c|c|c|c|c|c|c|c|c|}
\hline \multirow[t]{3}{*}{ Independent variables } & \multicolumn{2}{|c|}{ Univariate } & \multicolumn{6}{|c|}{ Multivariate } \\
\hline & \multirow[t]{2}{*}{$r$} & \multirow[t]{2}{*}{$p$} & \multicolumn{2}{|l|}{ Model 1} & \multicolumn{2}{|l|}{ Model 2} & \multicolumn{2}{|l|}{ Model 3} \\
\hline & & & $\beta$ & $p$ & $\beta$ & $P$ & $\beta$ & $p$ \\
\hline \multicolumn{9}{|l|}{ (a) } \\
\hline HbA1c CV (\%) & -0.354 & 0.007 & -0.341 & 0.020 & -0.359 & 0.014 & -0.339 & 0.014 \\
\hline Two-year mean HbA1c (\%) & -0.384 & 0.003 & -0.073 & 0.641 & -0.052 & 0.741 & -0.006 & 0.969 \\
\hline CGM CV (mg/dL) & -0.325 & 0.014 & -0.288 & 0.035 & -0.308 & 0.025 & -0.229 & 0.072 \\
\hline Age (years) & -0.358 & 0.006 & -0.323 & 0.008 & -0.330 & 0.006 & -0.302 & 0.008 \\
\hline Sex (male/female) & - & 0.550 & -0.129 & 0.283 & -0.161 & 0.180 & -0.149 & 0.182 \\
\hline $\operatorname{BMI}\left(\mathrm{kg} / \mathrm{m}^{2}\right)$ & 0.006 & 0.965 & -0.221 & 0.120 & -0.205 & 0.127 & -0.159 & 0.212 \\
\hline $\mathrm{SBP}(\mathrm{mmHg})$ & 0.154 & 0.252 & 0.067 & 0.585 & - & - & - & - \\
\hline LDL-cholesterol (mg/dL) & 0.074 & 0.586 & - & - & 0.122 & 0.297 & - & - \\
\hline Heart rate (beats/min) & -0.446 & 0.001 & - & - & - & - & -0.300 & 0.011 \\
\hline \multicolumn{9}{|l|}{ (b) } \\
\hline HbA1c SD (\%) & -0.384 & 0.003 & -0.373 & 0.021 & -0.395 & 0.014 & -0.371 & 0.014 \\
\hline Two-year mean HbA1c (\%) & -0.384 & 0.003 & -0.020 & 0.906 & 0.006 & 0.971 & 0.048 & 0.769 \\
\hline CGM CV (mg/dL) & -0.325 & 0.014 & -0.288 & 0.035 & -0.309 & 0.025 & -0.230 & 0.071 \\
\hline Age (years) & -0.358 & 0.006 & -0.322 & 0.008 & -0.328 & 0.006 & -0.301 & 0.008 \\
\hline Sex (male/female) & - & 0.550 & -0.130 & 0.278 & -0.163 & 0.176 & -0.150 & 0.179 \\
\hline $\operatorname{BMI}\left(\mathrm{kg} / \mathrm{m}^{2}\right)$ & 0.006 & 0.965 & -0.228 & 0.111 & -0.215 & 0.113 & -0.167 & 0.192 \\
\hline $\mathrm{SBP}(\mathrm{mmHg})$ & 0.154 & 0.252 & 0.064 & 0.606 & - & - & - & - \\
\hline LDL-cholesterol (mg/dL) & 0.074 & 0.586 & - & - & 0.123 & 0.290 & - & - \\
\hline Heart rate (beats/min) & -0.446 & 0.001 & - & - & - & - & -0.299 & 0.011 \\
\hline \multicolumn{9}{|l|}{ (c) } \\
\hline Adjusted HbA1c SD (\%) & -0.391 & 0.003 & -0.376 & 0.020 & -0.397 & 0.014 & -0.376 & 0.013 \\
\hline Two-year mean HbA1c (\%) & -0.384 & 0.003 & -0.017 & 0.919 & 0.007 & 0.967 & 0.051 & 0.752 \\
\hline CGM CV (mg/dL) & -0.325 & 0.014 & -0.290 & 0.034 & -0.309 & 0.025 & -0.231 & 0.070 \\
\hline Age (years) & -0.358 & 0.006 & -0.318 & 0.009 & -0.325 & 0.007 & -0.297 & 0.009 \\
\hline Sex (male/female) & - & 0.550 & -0.131 & 0.273 & -0.163 & 0.173 & -0.152 & 0.174 \\
\hline $\operatorname{BMI}\left(\mathrm{kg} / \mathrm{m}^{2}\right)$ & 0.006 & 0.965 & -0.227 & 0.111 & -0.213 & 0.115 & -0.166 & 0.193 \\
\hline $\mathrm{SBP}(\mathrm{mmHg})$ & 0.154 & 0.252 & 0.065 & 0.596 & - & - & - & - \\
\hline LDL-cholesterol (mg/dL) & 0.074 & 0.586 & - & - & 0.122 & 0.297 & - & - \\
\hline Heart rate (beats/min) & -0.446 & 0.001 & - & - & - & - & -0.301 & 0.010 \\
\hline
\end{tabular}

Dependent variable was baroreflex sensitivity, and the independent variables were Model 1, Model 2, and Model 3. Model 1: age, sex, BMI, CGM CV, mean HbA1C, visit-to-visit HbA1c variability, and SBP; Model 2: age, sex, BMI, CGM CV, mean HbA1c, visit-to-visit HbA1c variability, and LDL-cholesterol; Model 3: age, sex, BMI, CGM $\mathrm{CV}$, mean HbA1c, visit-to-visit HbA1c variability, and heart rate; Visit-to-visit HbA1c variability was (a) HbA1c CV (b) HbA1c SD, and (c) adjusted HbA1c SD; Model 1 (a) R-squared 0.398, adjusted R-squared 0.312, (b) R-squared 0.398, adjusted R-squared 0.312, (c) R-squared 0.399, adjusted R-squared 0.313; Model 2 (a) R-squared 0.408, adjusted R-squared 0.324, (b) R-squared 0.409, adjusted R-squared 0.324, (c) R-squared 0.409, adjusted R-squared 0.325; Model 3 (a) R-squared 0.471, adjusted R-squared 0.395, (b) R-squared 0.471, adjusted R-squared 0.395, (c) R-squared 0.472, adjusted R-squared 0.397

$C V$ coefficient of variation, $S D$ standard deviation, $C G M$ continuous glucose monitoring, $B M I$ body mass index, $S B P$ systolic blood pressure, $L D L$ low-density lipoprotein

this phenomenon is difficult to prevent or ameliorate by anti-diabetic drugs, these conditions persist for long periods and the autonomic dysfunction possibly becomes irreversible or worsens. Furthermore, insulin resistance may be one possible explanation of the result showing that increased visit-to-visit HbA1c variability was related to reduced BRS, because GV is known to be associated with insulin resistance [46]. Insulin resistance was shown to be associated with sympathetic activity [47], which is a determinant of BRS [48]. Although it was previously reported that long-term GV was associated with the severity of CAN compared to short-term GV [16], in this study the effects of long-term GV and short-term GV on reduced BRS were comparable. Furthermore, an additional reduction in BRS was not shown in participants with both long-term GV and short-term GV values above the median (Table 4, Fig. 4). Although endothelial function, oxidative stress, and insulin resistance were 
Table 4 Respective and combined effects of short-term and long-term glycemic variability on baroreflex sensitivity

\begin{tabular}{|c|c|c|c|c|c|c|}
\hline Variables & $\begin{array}{l}\text { Group } 1 \\
(n=16)\end{array}$ & $\begin{array}{l}\text { Group } 2 \\
(n=13)\end{array}$ & $\begin{array}{l}\text { Group } 3 \\
(n=13)\end{array}$ & $\begin{array}{l}\text { Group } 4 \\
(n=15)\end{array}$ & $p$ value $^{\S}$ & $\begin{array}{l}\text { Test for trend } \\
p \text { value }\end{array}$ \\
\hline \multicolumn{7}{|l|}{$\mathrm{BRS}$ (msec/mmHg) } \\
\hline Mean \pm SD & $9.58 \pm 3.0$ & $7.10 \pm 1.9^{*}$ & $6.64 \pm 2.2^{*}$ & $6.66 \pm 2.4^{*}$ & 0.004 & 0.002 \\
\hline$p$ value & & 0.045 & 0.012 & 0.009 & & \\
\hline Age (years) & $66.9 \pm 5.6$ & $67.2 \pm 7.5$ & $65.9 \pm 8.4$ & $68.6 \pm 9.6$ & 0.840 & \\
\hline Diabetes duration (years) & $8.3 \pm 8.2$ & $14.3 \pm 12.4$ & $8.2 \pm 4.2$ & $15.4 \pm 10.4$ & 0.069 & \\
\hline CGM CV (mg/dL) & $18.3 \pm 2.5$ & $29.5 \pm 5.5^{*}$ & $18.1 \pm 3.5^{\dagger}$ & $29.1 \pm 5.9^{* \neq}$ & 0.000 & \\
\hline Two-year mean HbA1c (\%) & $6.6 \pm 0.4$ & $6.8 \pm 0.8$ & $7.6 \pm 0.8^{*}$ & $7.8 \pm 1.1^{* \dagger}$ & 0.000 & \\
\hline HbA1c CV (\%) & $0.030(0.024-0.044)$ & $0.027(0.021-0.033)$ & $0.065(0.060-0.114)^{* \dagger}$ & $0.082(0.064-0.107)^{* \dagger}$ & 0.000 & \\
\hline
\end{tabular}

Values are mean \pm SD or median (25th-75th percentiles). Group 1, both CGM CV and HbA1c CV below median CV value. Group 2, CGM CV only above median. Group 3, HbA1c CV only above median. Group 4, both CGM CV and HbA1c CV above median values

$B R S$ baroreflex sensitivity, CV coefficient of variation, SD standard deviation, CGM continuous glucose monitoring

Results of the Tukey post hoc test, the Games-Howell post hoc test, or the Bonferroni post hoc test (1) compared with Group 1: * $p<0.05$; (2) compared with Group 2: ${ }^{\dagger} p<0.05$; (3) compared with Group $3:{ }^{\ddagger} p<0.05$

$\S$ The analysis of variance (ANOVA) or the Kruskal-Wallis test was used to compare BRS among the four groups

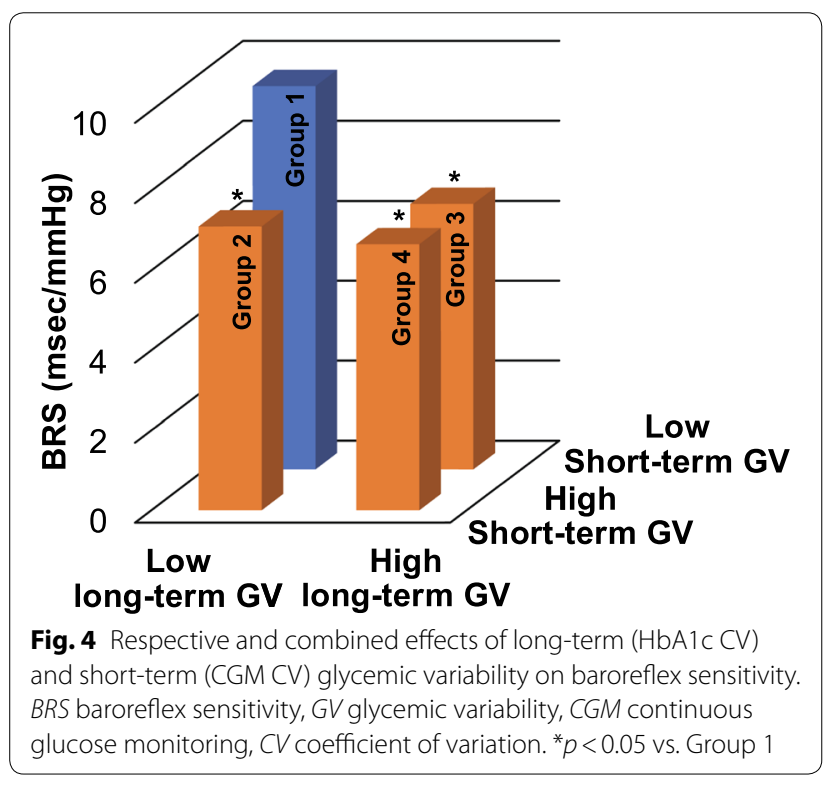

not examined in this study, an increase in either longterm GV or short-term GV reduces BRS to some extent by these physiological mechanisms and BRS might have reached a steady state in these study participants. In addition, our results may have been due to the fact that the evaluation period for long-term GV of 2 years was insufficient, and the duration of hypertension and the state of its management were not evaluated.

On the other hand, in subgroup analysis, patients taking sulfonylurea had larger visit-to-visit HbA1c variability than those who did not. Furthermore, sulfonylureas were associated with reduced BRS (Table 5). Sulfonylureas are prescribed typically for T2DM in patients with relative difficulty in glycemic control, such as those with a long duration of diabetes and low insulin levels. Furthermore, sulfonylureas present a high risk of causing hypoglycemia [49-51], and as a result visit-to-visit HbA1c variability may have increased in those patients taking sulfonylureas.

In addition to long-term $\mathrm{GV}$, as previously reported $[9,10]$, because our study showed that age and heart rate were independently correlated with BRS, these factors are important to consider when assessing BRS, especially in elderly patients with T2DM and a high heart rate. It is known that loss of arterial distensibility is the major mechanism responsible for the reduction of BRS in elderly patients [52]. Since the baroreflex modulates the heart rate, the association of BRS with heart rate is not unexpected. A low heart rate indicates high vagal tone, which usually accompanies high BRS [53]. On the other hand, unlike previous reports [9-14], we did not find a significant correlation of BRS with blood pressure, BMI, and lipid metabolism variables. That this study enrolled patients who were taking antihypertensive agents and/or lipid lowering agents that may improve BRS [54-56] might have influenced the results.

This study has four notable limitations. First, in this retrospective study, only 57 patients were enrolled and analyzed. Second, the period studied was short, that is, only 2 years, and changes in anti-diabetic drugs were not considered during the 2-year period. Third, factors related to drugs that could affect BRS, such as antihypertensive agents and/or lipid-lowering agents, were not considered. Fourth, this study did not investigate short-term GV and long-term GV simultaneously and prospectively. 
Table 5 Comparison of baroreflex sensitivity according to subgroups

\begin{tabular}{|c|c|c|c|c|c|c|c|c|c|}
\hline Subgroup & No (\%) & HbA1c CV (\%) & $p$ value & HbA1c SD (\%) & $p$ value & $\begin{array}{l}\text { Adjusted HbA1c } \\
\text { SD (\%) }\end{array}$ & $p$ value & $\begin{array}{l}\text { BRS (msec/ } \\
\mathrm{mmHg} \text { ) }\end{array}$ & $p$ value \\
\hline Sex & & & 0.140 & & 0.186 & & 0.181 & & 0.550 \\
\hline Male & $39(68)$ & $0.053(0.032-0.082)$ & & $0.37(0.23-0.66)$ & & $0.36(0.23-0.64)$ & & $7.7 \pm 2.7$ & \\
\hline Female & $18(32)$ & $0.040(0.021-0.070)$ & & $0.29(0.13-0.59)$ & & $0.27(0.13-0.57)$ & & $7.3 \pm 2.8$ & \\
\hline Hypertension & & & 0.088 & & 0.107 & & 0.095 & & 0.011 \\
\hline Yes & $42(74)$ & $0.055(0.032-0.090)$ & & $0.40(0.24-0.67)$ & & $0.39(0.23-0.64)$ & & $7.0 \pm 2.5^{*}$ & \\
\hline No & $15(26)$ & $0.032(0.026-0.059)$ & & $0.21(0.17-0.62)$ & & $0.20(0.16-0.59)$ & & $9.1 \pm 2.9$ & \\
\hline Dyslipidemia & & & 0.585 & & 0.694 & & 0.713 & & 0.903 \\
\hline Yes & $51(89)$ & 0.049 (0.029-0.089) & & $0.33(0.18-0.66)$ & & $0.31(0.18-0.64)$ & & $7.6 \pm 2.6$ & \\
\hline No & $6(11)$ & $0.051(0.024-0.060)$ & & $0.33(0.15-0.51)$ & & $0.32(0.14-0.49)$ & & $7.7 \pm 3.7$ & \\
\hline Insulin use & & & 0.422 & & 0.233 & & 0.223 & & 0.655 \\
\hline Yes & $6(11)$ & $0.061(0.042-0.091)$ & & $0.54(0.32-0.83)$ & & $0.52(0.31-0.80)$ & & $7.1 \pm 3.8$ & \\
\hline No & $51(89)$ & $0.048(0.028-0.082)$ & & $0.32(0.18-0.63)$ & & $0.31(0.17-0.59)$ & & $7.6 \pm 2.6$ & \\
\hline Sulfonylurea use & & & 0.043 & & 0.018 & & 0.015 & & 0.028 \\
\hline Yes & $17(30)$ & $0.065(0.035-0.103)^{*}$ & & $0.60(0.26-0.88)^{*}$ & & $0.59(0.25-0.85)^{*}$ & & $6.4 \pm 2.1^{*}$ & \\
\hline No & $40(70)$ & $0.047(0.025-0.065)$ & & $0.32(0.16-0.47)$ & & $0.30(0.16-0.46)$ & & $8.1 \pm 2.8$ & \\
\hline Statin use & & & 0.108 & & 0.132 & & 0.124 & & 0.035 \\
\hline Yes & $20(35)$ & $0.062(0.041-0.105)$ & & $0.45(0.27-0.80)$ & & $0.44(0.26-0.76)$ & & $6.6 \pm 2.6^{*}$ & \\
\hline No & $37(65)$ & $0.047(0.027-0.065)$ & & $0.32(0.17-0.51)$ & & $0.30(0.16-0.49)$ & & $8.1 \pm 2.6$ & \\
\hline RAAS inhibitor use & & & 0.635 & & 0.600 & & 0.544 & & 0.526 \\
\hline Yes & $22(39)$ & $0.049(0.032-0.069)$ & & $0.35(0.24-0.52)$ & & $0.34(0.23-0.50)$ & & $7.3 \pm 2.6$ & \\
\hline No & $35(61)$ & $0.049(0.027-0.089)$ & & $0.32(0.17-0.63)$ & & $0.30(0.17-0.60)$ & & $7.8 \pm 2.8$ & \\
\hline CCB use & & & 0.272 & & 0.349 & & 0.324 & & 0.241 \\
\hline Yes & $24(42)$ & $0.062(0.030-0.087)$ & & $0.44(0.24-0.65)$ & & $0.43(0.23-0.63)$ & & $7.1 \pm 2.4$ & \\
\hline No & $33(58)$ & $0.045(0.028-0.080)$ & & $0.31(0.18-0.63)$ & & $0.30(0.17-0.59)$ & & $7.9 \pm 2.9$ & \\
\hline Beta-blocker use & & & 0.902 & & 1.000 & & 0.989 & & 0.462 \\
\hline Yes & $5(9)$ & $0.048(0.027-0.085)$ & & $0.33(0.20-0.71)$ & & $0.32(0.19-0.69)$ & & $8.4 \pm 3.7$ & \\
\hline No & $52(91)$ & $0.050(0.028-0.081)$ & & $0.33(0.18-0.63)$ & & $0.31(0.17-0.60)$ & & $7.5 \pm 2.6$ & \\
\hline
\end{tabular}

Values are mean $\pm S D$, median (25th-75th percentiles) or no. (\%)

$B R S$ baroreflex sensitivity, $C V$ coefficient of variation, $S D$ standard deviation, $R A A S$ renin-angiotensin-aldosterone system, $C C B$ calcium-channel blocker * $p$ value corresponds to the Student's $t$ test or the non-parametric Mann-Whitney $U$-test

\section{Conclusions}

Visit-to-visit HbA1c variability was inversely related to BRS independently of mean HbA1c in patients with T2DM. Therefore visit-to-visit HbA1c variability might be a marker of reduced BRS in T2DM. Future studies are awaited to focus on the pathophysiology of CAN assessed by BRS.

\section{Abbreviations}

BRS: baroreflex sensitivity; CAN: cardiovascular autonomic neuropathy; CGM: continuous glucose monitoring; GV: glycemic variability; T2DM: type 2 diabetes mellitus.

\section{Authors' contributions}

DM and MS contributed to the study design, data acquisition, and data analysis and wrote the manuscript. SM, YK, NT, RH, and KU reviewed and edited the intellectual content. All authors gave final approval for this version to be published. The funder had no role in study design, analysis, interpretation of data, writing of the manuscript, and the decision to submit the manuscript for publication. All authors read and approved the final manuscript.

\section{Author details}

${ }^{1}$ Division of Diabetes, Metabolism and Endocrinology, Department of Internal Medicine, Jikei University School of Medicine, 3-25-8, Nishi-Shinbashi, Minato-ku, Tokyo 105-8461, Japan. ${ }^{2}$ Department of Cardiology, Jikei University School of Medicine, 3-25-8, Nishi-Shinbashi, Minato-ku, Tokyo 105-8461, Japan. ${ }^{3}$ Department of Cardiovascular Medicine, Graduate School of Medicine, The University of Tokyo, 7-3-1, Hongo, Bunkyo-ku, Tokyo 113-8654, Japan.

${ }^{4}$ Department of Pathology, Tsuruoka Kyoritsu Hospital, 9-34, Fumizonomachi, Tsuruoka-shi, Yamagata 997-0816, Japan.

\section{Acknowledgements}

We thank Mio Yonaiyama for her work on this study.

\section{Competing interests}

The authors of this manuscript have the following competing interests: M.S. has participated in speaker's bureaus/advisory panels for Sanofi, DaiichiSankyo, Astellas, and Tanabe-Mitsubishi. N.T. has received a research grant and support from Daiichi-Sankyo and Otsuka Pharmaceutical and has participated in speaker's bureaus organized by Daiichi-Sankyo and MSD. K.U. has received research support from Terumo, Kowa, Taisho, Arkray, Kyowa Kirin, MSD, Astellas, Boehringer Ingelheim, Ono, Novo Nordisk, Kissei and Tanabe-Mitsubishi and has participated in speaker's bureau/advisory panels for Astellas, Astra Zeneca, 
Kowa, MSD, Eli Lilly, Taisho, Novo Nordisk and Sanofi. The other authors declare that they have no competing interests.

\section{Availability of data and materials}

The datasets used and/or analyzed during the current study are available from the corresponding author on reasonable request.

\section{Consent for publication}

Not applicable.

\section{Ethics approval and consent to participate}

The study protocol was approved by the local ethics committee, and the study was conducted according to the principles of the Helsinki Declaration II.

\section{Funding}

No specific funding was received for the study.

\section{Publisher's Note}

Springer Nature remains neutral with regard to jurisdictional claims in published maps and institutional affiliations.

\section{Received: 13 May 2018 Accepted: 4 July 2018}

Published online: 10 July 2018

\section{References}

1. Frattola A, Parati G, Gamba P, Paleari F, Mauri G, Di Rienzo M, Castiglioni P, Mancia G. Time and frequency domain estimates of spontaneous baroreflex sensitivity provide early detection of autonomic dysfunction in diabetes mellitus. Diabetologia. 1997:40(12):1470-5.

2. Ziegler D, Laude D, Akila F, Elghozi JL. Time- and frequency-domain estimation of early diabetic cardiovascular autonomic neuropathy. Clin Auton Res. 2001;11(6):369-76.

3. La Rovere MT, Specchia G, Mortara A, Schwartz PJ. Baroreflex sensitivity, clinical correlates, and cardiovascular mortality among patients with a first myocardial infarction. A prospective study. Circulation. 1988;78(4):816-24.

4. La Rovere MT, Pinna GD, Hohnloser SH, Marcus FI, Mortara A, Nohara R, Bigger JT Jr, Camm AJ, Schwartz PJ. Baroreflex sensitivity and heart rate variability in the identification of patients at risk for lifethreatening arrhythmias: implications for clinical trials. Circulation. 2001;103(16):2072-7.

5. Spallone V, Ziegler D, Freeman R, Bernardi L, Frontoni S, Pop-Busui R, Stevens M, Kempler P, Hilsted J, Tesfaye S, et al. Cardiovascular autonomic neuropathy in diabetes: clinical impact, assessment, diagnosis, and management. Diabetes Metab Res Rev. 2011;27(7):639-53.

6. Watkins LL, Surwit RS, Grossman P, Sherwood A. Is there a glycemic threshold for impaired autonomic control? Diabetes Care. 2000;23(6):826-30.

7. Gerritsen J, Dekker JM, TenVoorde BJ, Bertelsmann FW, Kostense PJ, Stehouwer CD, Heine RJ, Nijpels G, Heethaar RM, Bouter LM. Glucose tolerance and other determinants of cardiovascular autonomic function: the Hoorn Study. Diabetologia. 2000;43(5):561-70.

8. Wu JS, Lu FH, Yang YC, Chang SH, Huang YH, Chen JJ, Chang CJ. Impaired baroreflex sensitivity in subjects with impaired glucose tolerance, but not isolated impaired fasting glucose. Acta Diabetol. 2014:51(4):535-41.

9. Kardos A, Watterich G, de Menezes R, Csanady M, Casadei B, Rudas L. Determinants of spontaneous baroreflex sensitivity in a healthy working population. Hypertension. 2001;37(3):911-6.

10. Lantelme P, Khettab F, Custaud MA, Rial MO, Joanny C, Gharib C, Milon H. Spontaneous baroreflex sensitivity: toward an ideal index of cardiovascular risk in hypertension? J Hypertens. 2002;20(5):935-44.

11. Beske SD, Alvarez GE, Ballard TP, Davy KP. Reduced cardiovagal baroreflex gain in visceral obesity: implications for the metabolic syndrome. Am J Physiol Heart Circ Physiol. 2002;282(2):H630-5.

12. Parati G, Di Rienzo M, Bertinieri G, Pomidossi G, Casadei R, Groppelli A, Pedotti A, Zanchetti A, Mancia G. Evaluation of the baroreceptor-heart rate reflex by 24 -hour intra-arterial blood pressure monitoring in humans. Hypertension. 1988;12(2):214-22.
13. Reimann M, Rudiger H, Weiss N, Ziemssen T. Acute hyperlipidemia but not hyperhomocysteinemia impairs reflex regulation of the cardiovascular system. Atheroscler Suppl. 2015;18:8-15.

14. Reimann M, Julius U, Haink K, Lippold B, Tselmin S, Bornstein SR, Reichmann H, Rudiger $\mathrm{H}$, Ziemssen T. LDL apheresis improves deranged cardiovagal modulation in hypercholesterolemic patients. Atherosclerosis. 2010;213(1):212-7

15. Matsutani D, Sakamoto M, luchi H, Minato S, Suzuki H, Kayama Y, Takeda $\mathrm{N}$, Horiuchi R, Utsunomiya K. Glycemic variability in continuous glucose monitoring is inversely associated with baroreflex sensitivity in type 2 diabetes: a preliminary report. Cardiovasc Diabetol. 2018;17(1):36.

16. Jun JE, Jin SM, Baek J, Oh S, Hur KY, Lee MS, Lee MK, Kim JH. The association between glycemic variability and diabetic cardiovascular autonomic neuropathy in patients with type 2 diabetes. Cardiovasc Diabetol. 2015; $14: 70$

17. Jaiswal M, McKeon K, Comment N, Henderson J, Swanson S, Plunkett C, Nelson P, Pop-Busui R. Association between impaired cardiovascular autonomic function and hypoglycemia in patients with type 1 diabetes. Diabetes Care. 2014;37(9):2616-21.

18. Nyiraty S, Pesei F, Orosz A, Coluzzi S, Vagi OE, Lengyel C, Abraham G, Frontoni S, Kempler P, Varkonyi T. Cardiovascular autonomic neuropathy and glucose variability in patients with type 1 diabetes: is there an association? Front Endocrinol (Lausanne). 2018;9:174

19. Cardoso CRL, Leite NC, Moram CBM, Salles GF. Long-term visit-to-visit glycemic variability as predictor of micro- and macrovascular complications in patients with type 2 diabetes: the Rio de Janeiro Type 2 Diabetes Cohort Study. Cardiovasc Diabetol. 2018;17(1):33.

20. Gorst C, Kwok CS, Aslam S, Buchan I, Kontopantelis E, Myint PK, Heatlie G, Loke Y, Rutter MK, Mamas MA. Long-term glycemic variability and risk of adverse outcomes: a systematic review and meta-analysis. Diabetes Care. 2015;38(12):2354-69.

21. Hirakawa Y, Arima H, Zoungas S, Ninomiya T, Cooper M, Hamet P, Mancia G, Poulter N, Harrap S, Woodward M, et al. Impact of visit-to-visit glycemic variability on the risks of macrovascular and microvascular events and all-cause mortality in type 2 diabetes: the ADVANCE trial. Diabetes Care. 2014;37(8):2359-65.

22. Muggeo M, Zoppini G, Bonora E, Brun E, Bonadonna RC, Moghetti $P$, Verlato G. Fasting plasma glucose variability predicts 10-year survival of type 2 diabetic patients: the Verona Diabetes Study. Diabetes Care. 2000;23(1):45-50.

23. Jun JE, Lee SE, Lee YB, Ahn JY, Kim G, Jin SM, Hur KY, Lee MK, Kim JH. Glycated albumin and its variability as an indicator of cardiovascular autonomic neuropathy development in type 2 diabetic patients. Cardiovasc Diabetol. 2017;16(1):127.

24. Kilpatrick ES, Rigby AS, Atkin SL. A1C variability and the risk of microvascular complications in type 1 diabetes: data from the Diabetes Control and Complications Trial. Diabetes Care. 2008:31(11):2198-202.

25. La Rovere MT, Pinna GD, Raczak G. Baroreflex sensitivity: measurement and clinical implications. Ann Noninvasive Electrocardiol. 2008;13(2):191-207.

26. Parlow J, Viale JP, Annat G, Hughson R, Quintin L. Spontaneous cardiac baroreflex in humans. Comparison with drug-induced responses. Hypertension 1995:25(5):1058-68.

27. Takenouchi A, Tsuboi A, Terazawa-Watanabe M, Kurata M, Fukuo K, Kazumi T. Direct association of visit-to-visit $\mathrm{HbA} 1 \mathrm{c}$ variation with annual decline in estimated glomerular filtration rate in patients with type 2 diabetes. J Diabetes Metabol Disord. 2015;14:69.

28. Takao T, Ide T, Yanagisawa H, Kikuchi M, Kawazu S, Matsuyama Y. The effect of fasting plasma glucose variability on the risk of retinopathy in type 2 diabetic patients: retrospective long-term follow-up. Diabetes Res Clin Pract. 2010;89(3):296-302.

29. Standl E, Schnell O, Ceriello A. Postprandial hyperglycemia and glycemic variability: should we care? Diabetes Care. 2011;34(Suppl 2):S120-7.

30. Su G, Mi SH, Li Z, Tao H, Yang HX, Zheng H. Prognostic value of early in-hospital glycemic excursion in elderly patients with acute myocardial infarction. Cardiovasc Diabetol. 2013;12:33.

31. Kuroda M, Shinke T, Sakaguchi K, Otake H, Takaya T, Hirota Y, Osue T, Kinutani H, Konishi A, Takahashi H, et al. Association between daily glucose fluctuation and coronary plaque properties in patients receiving adequate lipid-lowering therapy assessed by continuous glucose 
monitoring and optical coherence tomography. Cardiovasc Diabetol. 2015;14:78.

32. Kuroda M, Shinke T, Otake H, Sugiyama D, Takaya T, Takahashi H, Terashita D, Uzu K, Tahara N, Kashiwagi D, et al. Effects of daily glucose fluctuations on the healing response to everolimus-eluting stent implantation as assessed using continuous glucose monitoring and optical coherence tomography. Cardiovasc Diabetol. 2016;15:79.

33. Mo Y, Zhou J, Li M, Wang Y, Bao Y, Ma X, Li D, Lu W, Hu C, Li M, et al. Glycemic variability is associated with subclinical atherosclerosis in Chinese type 2 diabetic patients. Cardiovasc Diabetol. 2013;12:15.

34. Su G, Mi S, Tao H, Li Z, Yang H, Zheng H, Zhou Y, Ma C. Association of glycemic variability and the presence and severity of coronary artery disease in patients with type 2 diabetes. Cardiovasc Diabetol. 2011;10:19.

35. Wei F, Sun X, Zhao Y, Zhang H, Diao Y, Liu Z. Excessive visit-to-visit glycemic variability independently deteriorates the progression of endothelial and renal dysfunction in patients with type 2 diabetes mellitus. BMC Nephrol. 2016;17(1):67.

36. Ceriello A, Esposito K, Piconi L, Ihnat MA, Thorpe JE, Testa R, Boemi M, Giugliano D. Oscillating glucose is more deleterious to endothelial function and oxidative stress than mean glucose in normal and type 2 diabetic patients. Diabetes. 2008;57(5):1349-54.

37. Costantino S, Paneni F, Battista R, Castello L, Capretti G, Chiandotto S, Tanese L, Russo G, Pitocco D, Lanza GA, et al. Impact of glycemic variability on chromatin remodeling, oxidative stress, and endothelial dysfunction in patients with type 2 diabetes and with target $\mathrm{HbA1c}$ levels. Diabetes. 2017;66(9):2472-82.

38. Ceriello A, Esposito K, Piconi L, Ihnat M, Thorpe J, Testa R, Bonfigli AR, Giugliano D. Glucose "peak" and glucose "spike": impact on endothelial function and oxidative stress. Diabetes Res Clin Pract. 2008;82(2):262-7.

39. Cameron NE, Eaton SE, Cotter MA, Tesfaye S. Vascular factors and metabolic interactions in the pathogenesis of diabetic neuropathy. Diabetologia. 2001:44(11):1973-88.

40. Nukada H. Ischemia and diabetic neuropathy. Handb Clin Neurol. 2014;126:469-87.

41. Dyck PJ. Hypoxic neuropathy: does hypoxia play a role in diabetic neuropathy? The 1988 Robert Wartenberg lecture. Neurology. 1989;39(1):111-8.

42. Emanuel AL, Nieuwenhoff MD, Klaassen ES, Verma A, Kramer MH, Strijers R, Vrancken AF, Eringa E, Groeneveld GJ, Serne EH. Relationships between type 2 diabetes, neuropathy, and microvascular dysfunction: evidence from patients with cryptogenic axonal polyneuropathy. Diabetes Care. 2017:40(4):583-90.

43. Monnier L, Mas E, Ginet C, Michel F, Villon L, Cristol JP, Colette C. Activation of oxidative stress by acute glucose fluctuations compared with sustained chronic hyperglycemia in patients with type 2 diabetes. JAMA. 2006;295(14):1681-7.

44. Vincent AM, Russell JW, Low P, Feldman EL. Oxidative stress in the pathogenesis of diabetic neuropathy. Endocr Rev. 2004;25(4):612-28.

45. Feldman EL. Oxidative stress and diabetic neuropathy: a new understanding of an old problem. J Clin Invest. 2003;111(4):431-3.

46. Liang S, Yin H, Wei C, Xie L, He H, Liu X. Glucose variability for cardiovascular risk factors in type 2 diabetes: a meta-analysis. J Diabetes Metabol Disord. 2017:16:45.

47. Kaaja RJ, Poyhonen-Alho MK. Insulin resistance and sympathetic overactivity in women. J Hypertens. 2006;24(1):131-41.

48. Skrapari I, Tentolouris N, Perrea D, Bakoyiannis C, Papazafiropoulou A, Katsilambros N. Baroreflex sensitivity in obesity: relationship with cardiac autonomic nervous system activity. Obesity (Silver Spring, Md). 2007;15(7):1685-93.

49. Tschope D, Bramlage P, Binz C, Krekler M, Plate T, Deeg E, Gitt AK. Antidiabetic pharmacotherapy and anamnestic hypoglycemia in a large cohort of type 2 diabetic patients - an analysis of the DiaRegis registry. Cardiovasc Diabetol. 2011;10:66.

50. Palmer SC, Mavridis D, Nicolucci A, Johnson DW, Tonelli M, Craig JC, Maggo J, Gray V, De Berardis G, Ruospo M, et al. Comparison of clinical outcomes and adverse events associated with glucose-lowering drugs in patients with type 2 diabetes: a meta-analysis. JAMA. 2016;316(3):313-24.

51. Kim G, Oh S, Jin SM, Hur KY, Kim JH, Lee MK. The efficacy and safety of adding either vildagliptin or glimepiride to ongoing metformin therapy in patients with type 2 diabetes mellitus. Expert Opin Pharmacother. 2017:18(12):1179-86.

52. Bonyhay I, Jokkel G, Kollai M. Relation between baroreflex sensitivity and carotid artery elasticity in healthy humans. Am J Physiol. 1996;271 (3 Pt 2):H1139-44.

53. Head GA. Baroreflexes and cardiovascular regulation in hypertension. J Cardiovasc Pharmacol. 1995;26(Suppl 2):S7-16.

54. Chern CM, Hsu HY, Hu HH, Chen YY, Hsu LC, Chao AC. Effects of atenolol and losartan on baroreflex sensitivity and heart rate variability in uncomplicated essential hypertension. J Cardiovasc Pharmacol. 2006:47(2):169-74.

55. Ylitalo A, Airaksinen KE, Sellin L, Huikuri HV. Effects of combination antihypertensive therapy on baroreflex sensitivity and heart rate variability in systemic hypertension. Am J Cardiol. 1999;83(6):885-9.

56. Grigoropoulou P, Eleftheriadou I, Zoupas C, Makrilakis K, Papassotiriou I, Margeli A, Perrea D, Katsilambros N, Tentolouris N. Effect of atorvastatin on baroreflex sensitivity in subjects with type 2 diabetes and dyslipidaemia. Diabetes Vasc Dis Res. 2014;11(1):26-33.
Ready to submit your research? Choose BMC and benefit from:

- fast, convenient online submission

- thorough peer review by experienced researchers in your field

- rapid publication on acceptance

- support for research data, including large and complex data types

- gold Open Access which fosters wider collaboration and increased citations

- maximum visibility for your research: over $100 \mathrm{M}$ website views per year

At $\mathrm{BMC}$, research is always in progress.

Learn more biomedcentral.com/submissions 